THU0445

PRIMARY DIAGNOSIS OF LARGE VESSEL VASCULITIS BY TISSUE HISTOLOGY AFTER SURGERY OF AORTIC VALVE AND ASCENDING AORTA

G. Assmann ${ }^{1}$, I. Karliova ${ }^{2}$, F. Langer ${ }^{2}$, M. Schreiber ${ }^{3}$, M. Pfreundschuh ${ }^{1}$, H.J. Schaefers ${ }^{2} .{ }^{1}$ Rheumatology and Oncology; ${ }^{2}$ Thoracic Surgery; ${ }^{3}$ Radiology Imaging, University Medical School of Saarland, Homburg, Germany

Background: Large vessel vasculitis showed different histological patterns, ranging from well-formed granulomas and lymphoplasmacytic pattern to giant cell pattern. Most of entities of large vessel vasculitis belong to rheumatic diseases such as the giant cell arteritis (GCA). The clinical feature is very variable depending on the GCA manifestations.

Objectives: Here we present an observation study of non-vasculitis patients, which had to undergo surgery of aortic valve and/or ascending aorta with a tissue histology of aortic inflammation.

Methods: In the department of thoracic surgery of the University Medical School of Saarland, Germany, 1474 patients (in $2014 \mathrm{n}=806$, in $2015 \mathrm{n}=668$ ) underwent thoracic surgery of aortic valve or ascending aorta due to different indications such as any entity of aortic aneurysm, dissection, aortic stenosis and/or insufficiency. Patients with bacterial endocarditis were excluded from analysis. All surgical specimens were pathologically analysed according standard procedure. All specimens ( $n=19$ in 2014, $n=17$ in 2015) with histological inflammation signs of aortitis being negative for tbc, mycosis, or lues were underwent further investigation searching for IgG4 +plasmacells, giant cells, and granuloma; all patients $(n=36)$ were re-evaluated by a rheumatologist (immediately during the hospitalisation or within 3 weeks with outpatient presentation) including laboratory tests for RF, ANA, ANCA, ACCP, IgG subclasses, complement, ESR, CRP. Furthermore, all aortitis patients were investigated with MRI of aorta $(n=15)$ or PET scan $(n=17)$ or both $(n=4)$ between 4 to 12 weeks after surgery to exclude persistent aortitis in native vessels. All patients which were diagnosed for aortitis through MRI and/or PET received immunosuppressive treatment containing glucocorticosteroids with or without synthetical or biological DMARDs.

Results: Patients after thoracic surgery of aortic valve and/or ascending aorta were positive tested for aortitis in 2014 with the frequency of $2.36 \%$ ( $n=19 / 806)$ and in $20152.54 \%(n=17 / 668)$. The mean age of the 36 cases were 61 (range 39$80)$, of them were male $55.5 \%(n=20)$. The pathologic findings described 14 cases typical for GCA, 6 with granuloma, one with IgG4 +plasmacells, and one with predominant lymphocytic infiltration, 14 with unspecific inflammation. Rheumatologic consultation in all 36 cases could evaluated in 6 patients a preexisting rheumatologic disorder (RA $n=2$, polymyalgia rheumatica $(P M R) n=4$ ) without treatment. One patient were positive for significant elevated serum levels of lgG4. MRI and/ or PET scan documented aortitis spots in the native aorta with or without concerning iliac arteries and/or supra-aortic vessels. All imaging-positive aortitis patients $(n=12)$ were treated with glucocorticosteroids according to the protocol for giant cell arteritis (prednisolone $1 \mathrm{mg} / \mathrm{Kg} /$ body weight), six patients additionally with methotrexate, one with tocilizumab and one with rituximab.

Conclusions: Only a small fraction of thoracic surgery patients with aortic aneurysm, dissection, aortic stenosis and/or insufficiency show histologic signs of aortitis. However, a third of them could be diagnosed via histological findings for active large vessel vasculitis after surgery.

Disclosure of Interest: None declared

DOI: 10.1136/annrheumdis-2018-eular.7406

\section{THU0446 USEFULNESS OF COLOUR DOPPLER ULTRASONOGRAPHY IN FOLLOW UP OF GIANT CELL ARTERITIS}

H. Mukoyama, K. Nishimura, K. Kadoba, R. Saito, D. Waki, T. Yokota. Department of Endocrinology and Rheumatology, Kurashiki Central Hospital, Kurashiki-shi, Okayama, Japan

Background: Colour doppler ultrasonography (CDU) in temporal arteries (TA) is useful for diagnosis and follow-up of giant cell arteritis (GCA). ${ }^{1}$ However, the usefulness of CDU in carotid arteries (CA) for follow-up of GCA is not fully understood. ${ }^{2}$ Objectives: We investigated retrospectively relationship between clinical features and vessel wall thickness of TA and CA on CDU at baseline and during follow-up.

Methods: We recruited patients with newly diagnosed GCA in our hospital from January in 2004 to July in 2017. Among 35 patients, both of TA and CA were evaluated by CDU before and after treatment in 14 patients (four male and 10 female). Trained ultrasonographers and rheumatologists evaluated the CDU findings. Vessel wall thickness was evaluated at thickest portion of parietal or frontal ramus of TA, where biopsy was often performed. Intima-media thickness (IMT) of CA was also evaluated at thickest portion in each carotid artery.

Results: Average age was $73.2 \pm 11.3$ years old. Follow-up periods after starting treatment were $244 \pm 149$ weeks. All patients were diagnosed as GCA according to ACR criteria (1990) or temporal artery biopsy. Twelve patients were complicated with polymyalgia rheumatica (PMR) meeting EULAR/.ACR classification criteria
(2012). All patients were treated with oral glucocorticoids $(0.2$ to $1.0 \mathrm{mg} / \mathrm{kg}$ prednisolone, $0.886 \mathrm{mg} / \mathrm{kg}$ on average). Immunosuppressants were added in four patients (methotrexate; $n=3$, tacrolimus; $n=1$ ). Aspirin was prescribed in nine patients.

Eleven patients $(78.6 \%)$ had circumferential hypoechoic vessel wall thickness (halo sign) of TA at baseline, and halo signs dissapeared in eight patients during follow-up. Average of vessel wall thickness significantly decreased from $0.665 \mathrm{~mm}$ to $0.311 \mathrm{~mm}(\mathrm{p}=0.0016)$. The vessel wall thickness apparently increased in two patients out of three on clinical relapse, but it didn't increase in those who kept remission.

Graphical changes consistent with vasculitis in CA were observed in six patients, who showed hypoechoic thick intima and media on ultrasound or integration of FDG on PET/CT. Average of IMT in CA decreased from $1.167 \mathrm{~mm}$ to $0.883 \mathrm{~mm}$ $(p=0.090)$ during follow-up in patients with vasculitis on CA. IMT changed little in patients without vasculitis on CA. Improvement rate was significantly higher in CA-involved patients than in CA-non-involved patients $(p=0.043)$. IMT increased during follow-up in two CA-non-involved patients.

\begin{tabular}{lccc}
\multicolumn{4}{l}{ Abstract THU0446 - Table 1. Time-dependent change in vessel wall thickness of TA (mm) } \\
\hline & Baseline & $\begin{array}{c}\text { Follow- } \\
\text { up }\end{array}$ & Relapse \\
\hline Patient & 0.30 & 0.30 & 0.30 \\
$\begin{array}{l}1 \\
\text { Patient }\end{array}$ 2 & 0.63 & 0.30 & 0.60 \\
Patient & & 0.10 & 0.60 \\
3 & 0.63 & & \\
\hline
\end{tabular}

Abstract THU0446 - Table 2. Improvement rate of IMT in CA involved and non-involved patients

\begin{tabular}{lcccc}
\hline & \multicolumn{2}{c}{ IMT $(\mathrm{mm})$} & Rate(B/ & $\begin{array}{c}\text { Median follow-up period } \\
\text { (months) }\end{array}$ \\
\cline { 2 - 3 } & $\begin{array}{l}\text { Baseline } \\
{[\mathrm{A}]}\end{array}$ & $\begin{array}{c}\text { Follow-up } \\
{[\mathrm{B}]}\end{array}$ & A) & \\
\hline All $(\mathrm{n}=14)$ & 0.964 & 0.843 & 0.874 & 30.0 \\
CA involved $(\mathrm{n}=6)$ & 1.167 & 0.883 & 0.757 & 34.0 \\
CA non-involved & 0.813 & 0.813 & 1.000 & 27.6 \\
$(\mathrm{n}=8)$ & & & & \\
\hline
\end{tabular}

Difference in B/A between CA involved and non-involved: $p=0.043$ (Mann-Whitney U test)

Conclusions: CDU of temporal arteries is useful for follow-up of GCA. CDU of carotid arteries has limited usefulness only in CA-involved patients.

REFERENCES:

[1] Suelves AM, et al. Clin Ophthalmol. 2010; Nov 25;4:1383-4.

[2] Hafner F, et al. Eur J Clin Invest 2014; 44(3):249-256.

Disclosure of Interest: None declared

DOI: 10.1136/annrheumdis-2018-eular.4657

\section{THU0447 NO ADVANTAGE OF METHOTREXATE IN THE TREATMENT OF GIANT CELL ARTERITIS}

I. Monjo Henry ${ }^{1}$, on behalf of Luis Coronel ${ }^{2}$, Ignacio Castaño ${ }^{3}$, Diana Peiteado ${ }^{1}$, Sara García-Carazo ${ }^{1}$, Alejandro Balsa ${ }^{1}$, Eugenio de Miguel ${ }^{1} .{ }^{1}$ Rheumatology, Hospital Universitario La Paz, Madrid, Spain. ; ${ }^{2}$ Rheumatology, Hospital Universitario Nuestra Señora de la Candelaria, Santa Cruz de

Background: The high-dose glucocorticoids (GCs) are the mainstay of treatment in Giant Cell Arteritis (GCA). Patients treated with greater GCs dosages are at the greatest risk of morbidity. Immunosuppressive agents have been trialled in an effort to reduce toxicity from GCs and to improve efficacy of treatment. The results of one meta-analysis with the three trials that included methotrexate (MTX) showed a weak benefit in those patients receiving MTX, but the results were heterogeneous, with one trial showing significant benefit, while the other two did not. ${ }^{1}$ Objectives: To study the efficacy and safety of MTX adjunct to GCs in the treatment of GCA.

Methods: New-onset giant-cell arteritis initiating treatment of the disease was included in a retrospective observational study to compare treatment efficacy and safety. According to the treatment received the patients were divided two groups: GCs alone (group 1) and MTX and GCs (group 2). To avoid bias, we defined a subgroup of patients in which only patients who started MTX in the first trimester of treatment were included (group 3). As efficacy outcome the number of relapses and the cumulative dose of GCs at 6,12 and 24 months were collected. For safety, 
the number of emergency room visits, hospitalisation admissions and infections were investigated in the follow-up

Results: One hundred twenty- three patients were included, 74 (60.2\%) women, the mean age was 79,41 years old. Fifty-six (45.53\%) received GCs alone (group 1) and $67(54.48 \%)$ received GCs and MTX as an adjuvant treatment at some time during follow- up (group 2). 30 of these 83 patients $(24.39 \%$ of total patients) received MTX in the first trimester after diagnosis (group 3). The cumulative doses of GCs, number of patients with relapses, visits to the emergency room and hospitalisation admissions are shown in the table 1. In none of these variables there were statistically significant differences among the three groups, except for the number of patients with relapses, which was greater in group 2 than in group 1 $(p=0.03)$. The number of relapses in patients who received MTX early (group 3 ) was $56.7 \%$, in the rest of patients (who only received GCs and those who started MTX after the first trimester) was $52.69 \%-33.3 \%$ of the patients in group $3 \%$ and $21.5 \%$ of the rest of the patients presented infections.

\begin{tabular}{|c|c|c|c|c|c|}
\hline & $\begin{array}{l}\text { Group 1: } \\
\text { GCs } \\
\text { alone }\end{array}$ & $\begin{array}{c}\text { Grupo 2: } \\
\text { GCs+MTX at some } \\
\text { moment during the } \\
\text { follow-up }\end{array}$ & $\begin{array}{l}\text { Group 3: } \\
\text { GCs and } \\
\text { MTX since } \\
\text { 1st trimester }\end{array}$ & $\begin{array}{c}P \\
\text { group } \\
3 \text { vs (1 } \\
+2)\end{array}$ & $\begin{array}{l}\mathrm{P} \\
\text { group } \\
1 \text { vs } 2\end{array}$ \\
\hline $\begin{array}{l}\text { Cumulative GCs } \\
\text { doses at } 6 \text { month } \\
\text { (mg } \pm \text { SD) }\end{array}$ & $\begin{array}{r}6193 \\
\pm 6820\end{array}$ & $7028 \pm 11230$ & $5942,50 \pm 1827$ & 0.629 & 0.646 \\
\hline $\begin{array}{l}\text { Cumulative GCs } \\
\text { doses at } \\
12 \text { months (mg } \\
\pm \text { SD) }\end{array}$ & $\begin{array}{c}7772 \\
\pm 7154\end{array}$ & $8976 \pm 11148$ & $7987 \pm 2360$ & 0.759 & 0.897 \\
\hline $\begin{array}{l}\text { Cumulative GCs } \\
\text { doses at } \\
24 \text { months (mg } \\
\pm \text { SD) }\end{array}$ & $\begin{array}{c}9340 \\
\pm 7886\end{array}$ & $10814 \pm 11150$ & $9383 \pm 2522$ & 0.608 & 0.903 \\
\hline $\begin{array}{l}N^{\circ} \text { of patients with } \\
\text { relapses }\end{array}$ & $\begin{array}{c}20 / 56 \\
(35.71 \%)\end{array}$ & $42 / 67(62.69 \%)$ & $17 / 30(56.7 \%)$ & 0.430 & 0.003 \\
\hline $\begin{array}{l}\mathrm{N}^{\circ} \text { of patients with } \\
\text { emergency room } \\
\text { visits }\end{array}$ & $20(35 \%)$ & $22(32.8 \%)$ & $12(24 \%)$ & 0.508 & 0.849 \\
\hline $\begin{array}{l}\mathrm{N}^{\circ} \text { of patients } \\
\text { hospitalisation } \\
\text { admissions }\end{array}$ & $\begin{array}{c}16 \\
(28.57 \%)\end{array}$ & 21 (31.34\%) & $11(36.7 \%)$ & 0.370 & 0.844 \\
\hline
\end{tabular}

Conclusions: Whilst MTX have been used in an effort to reduce toxicity from GCs and to improve efficacy of treatment our observational study shows that there is no benefit from adjunct MTX in GCA either in terms of efficacy or toxicity.

\section{REFERENCE:}

[1] Mahr AD, Jover JA, Spiera RF, et al. Adjunctive methotrexate for treatment of giant cell arteritis: an individual patient data metaanalysis. Arthritis Rheum 2007;56(8):2789-2797.

Disclosure of Interest: None declared

DOI: 10.1136/annrheumdis-2018-eular.7148

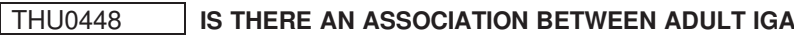 VASCULITIS AND CANCER?}

J. Ostrovršnik, Ž. Rotar, R. Ješe, M. Tomšič, A. Hočevar. Department of Rheumatology, University Medical Centre Ljubljana, Ljubljana, Slovenia

Background: An increased incidence rate of cancer has been reported in adult patients with $\lg A$ vasculitis ( $\lg A \mathrm{~V})$. These conclusions are mostly based on observations in severely ill, hospitalised subgroup of patients. Most of the studies allowed for a wide time interval between IgAV and cancer appearance, not necessarily reflecting a causative link.

Objectives: The aim of our study was to look for the potential association between IgAV and cancer in an unselected adult IgAV population.

Methods: We analysed medical records of prospectively followed, histologically proven adult IgAV cases at our secondary/tertiary rheumatology centre between 1 January 2010 and 30 June 2017, who were followed until 31 December 2017 and lived in a well-defined referral region. We identified cancer as concurrent with $\operatorname{lgAV}$, if the patients had active cancer or a relapse of cancer or newly-diagnosed cancer diagnosed up to 6 months prior or 6 months after IgAV diagnosis. Cancers developing after 6 months of follow up were labelled as unrelated to IgAV. We used appropriate descriptive statistical methods, and the Fisher's exact and Mann-Whitney $U$ tests to assess differences of clinical characteristics in acute phase of $\lg A \mathrm{~V}$, between the cancer and non-cancer groups. The national prevalence and age adjusted incidence rates of cancer from a well-defined referral region were obtained from National cancer registry (NCR).

Results: During the 90 months of observation we identified 196 new IgAV cases. 2 patients died in the acute disease phase due to vasculitis, and 8 during the first 6 months of follow-up for reasons other than $\lg A \mathrm{~V}$ or cancer. 20 patients were lost to follow-up. The remaining 166 patients (55\% male, median (IQR) age $63^{43-76}$ years) were followed for a median (IQR) of $20^{11-32}$ months. At the time of IgAV diagnosis, 6/166 (3.6\%) had active, previously diagnosed malignant disease (prostatic cancer in 4, among which one also had cancer of urinary bladder, and sarcoma in 2 patients). In $2 / 166$ patients (1.2\%) a new cancer was diagnosed at presentation and in 2/166 (1.2\%) during follow-up. One of the patients with an active cancer of urinary bladder, was treated with antibiotics for urinary tract infection prior to IgAV diagnosis, and was also on chemotherapy. The patients with cancer were older (median age (IQR) $80^{77-83}$ vs. $64^{44-77}$ years; $p=0.002$ ) but their presenting features of $\lg \mathrm{AV}$, and the initial $\lg \mathrm{AV}$ treatment did not significantly dif fer from those without cancer. At the end of the observation period, the prevalence of cancer in our cohort was $6.0 \%$, compared to the $4.8 \%$ prevalence of cancer in our general population and the relative risk of cancer in our $\operatorname{lgAV}$ cohort was 1.25 (95\% Cl 0.687-2.29; $p=0.461)$. The age adjusted incidence rate of cancer was 11.4 per 1000 patients per year. The annual age adjusted incidence rate of cancer in our citizens, acquired from NCR, was 8.9 per 1000 adults and the standardised incidence ratio for our IgAV cohort was 1.62 ( $\mathrm{Cl} 0.441-4.15 ; \mathrm{p}=0.472)$.

Conclusions: In our cohort of unselected adult IgAV cases, we did not confirm the previous observations of the association of $\lg A \mathrm{~V}$, and cancer.

Disclosure of Interest: None declared

DOI: 10.1136/annrheumdis-2018-eular.5359

\section{THU0449 DIAGNOSTIC PERFORMANCE OF ANTINEUTROPHIL CYTOPLASMIC ANTIBODIES IN A COHORT OF UNSELECTED SPANISH PATIENTS}

J. Loureiro-Amigo $^{1}$, J. Mestre Torres ${ }^{2}$, C.L. Franco Jarava ${ }^{3}$, A. Marín Sánchez ${ }^{3}$, R. Solans Laqué ${ }^{1} .{ }^{1}$ Internal Medicine - Autoimmune Diseases Division; ${ }^{2}$ Internal Medicine - Autoimmune Division; ${ }^{3}$ Immunology Division, Vall d'Hebron University Hospital, Barcelona, Spain

Background: Antineutrophil cytoplasmic antibodies (ANCA) are the serological marker of some idiopathic systemic vasculitides, predominantly involving small and medium-sized blood vessels, such as granulomatosis with polyangiitis (GPA), microscopic polyangiitis (MPA) and eosinophilic granulomatosis with poly angiitis (EGPA), which are known as the ANCA-associated vasculitis (AAV). Nevertheless, ANCA have been reported in a number of other conditions.

Objectives: To retrospectively evaluate ANCA diagnostic accuracy in a cohort of unselected patients.

Methods: From January 2014 to December 2016 a total of 6781 serum samples with a test request for ANCA were submitted to the Immunology Department of a 1.000-bed tertiary teaching hospital from Barcelona (Spain), from both inpatients and outpatients.

Indirect immunofluorescence (IIF) was performed for all requests using a commercially available "Granulocyte Mosaic 13" (EUROIMMUN). IIF allowed recognition of three staining patterns: cytoplasmic (cANCA), perinuclear (pANCA) and atypical (XANCA). For the detection of antibodies against mieloperoxidase (MPO) and proteinase 3 (PR3) a chemiluminescent immuno-assay (CLIA) using commercially available "QUANTA Flash MPO/PR3" (INOVA diagnostics) was performed in patients with positive IIF.

We reviewed the clinical charts of patients that underwent ANCA testing and collected patients' diagnoses, as established by their treating physician one year after sampling. In the event of multiple ANCA test in a single patient we include only the first test request (we excluded 1323 tests performed in 661 patients). We also excluded 184 patients with insufficient information and 306 ANCA tests with no diagnostic purpose. Therefore the study population includes 4968 patients.

Statistical analysis was performed with Stata 14.2 (College Station, TX, USA). Diagnostic performance was assessed using sensitivity, specificity, positive likelihood ratio (LR+), positive and negative predictive values (PPV and NPV) and global efficiency. Confidence Intervals $(\mathrm{Cl})$ were calculated using Wilson method. Results: Only 34 patients $(0.68 \%)$ received a diagnosis of AAV: 25 MPA, 6 GPA and 3 EGPA.

\begin{tabular}{lcccccc}
\hline & $\begin{array}{c}\text { Sensitivity } \\
{[\mathrm{Cl} 95 \%]}\end{array}$ & $\begin{array}{c}\text { Specificity } \\
{[\mathrm{Cl} 95 \%]}\end{array}$ & $\begin{array}{c}\text { LR+ } \\
{[\mathrm{Cl}} \\
95 \%]\end{array}$ & $\begin{array}{c}\text { PPV } \\
{[\mathrm{Cl}} \\
95 \%]\end{array}$ & $\begin{array}{c}\text { NPV } \\
{[\mathrm{Cl} 95 \%]}\end{array}$ & $\begin{array}{c}\text { Efficiency } \\
{[\mathrm{Cl} 95 \%]}\end{array}$ \\
\hline Positive IIF & $94.1 \%$ & $87.6 \%$ & 7.6 & $5 \%$ & $99.95 \%$ & $87.7 \%$ \\
& {$[80.9-$} & {$[86.7-$} & {$[6.8-$} & {$[3.5-$} & {$[99.83-$} & {$[86.7-$} \\
& $98.4]$ & $88.5]$ & $8.5]$ & $6.9]$ & $99.99]$ & $88.5]$ \\
IIF Typical pattern & $91.2 \%$ & $96.9 \%$ & 29 & $16.7 \%$ & $99.94 \%$ & $96.8 \%$ \\
& {$[77-97$} & {$[96.3-$} & {$[24.1-$} & {$[12-$} & {$[99.82-$} & {$[96.3-$} \\
& & $97.3]$ & $35]$ & $22.7]$ & $99.98]$ & $97.3]$ \\
cANCA/PR3 or & $76.5 \%$ & $99.1 \%$ & 83.8 & $36.6 \%$ & $99.84 \%$ & $98.9 \%$ \\
pANCA/MPO & {$[60-87.6]$} & {$[98.8-$} & {$[59.3-$} & {$[26.4-$} & {$[99.68-$} & {$[98.6-$} \\
& & $99.3]$ & $118.4]$ & $48.2]$ & $99.92]$ & $99.2]$ \\
\hline
\end{tabular}

The majority (87.1\%) of patients had a negative ANCA test and only $12.9 \%$ were found positive by IIF. Among 643 positive patients IIF pattern distribution was: 457 (71.1\%) atypical, 108 (16.8\%) perinuclear and 78 (12.1\%) cytoplasmic pattern. 